\title{
Chapter 18 \\ Hybridizing Artifice and Nature: \\ Designing New Soils Through \\ the Eco-Systemic Approach
}

\author{
Marina Rigillo
}

\subsection{A Paradigm Shift}

The increasing consciousness of being coping with complex and global challenges moves research interests towards more integrated approaches, explicitly posing the need of implementing the traditional top-down research methods (as for "hard sciences") with horizontal patterns, more collaborative and goal-oriented (Di Biase, 2016; Lazlo, 1985). This change has its theoretical roots in 1980s debate on both complexity and system theory, and it takes now more vigour from the current global trials (i.e.: climate change, resource consumption, and social challenges) (Bocchi \& Cerruti, 1985; Lazlo, 2008; Latour, 2018). ${ }^{1}$ The interest for such a new research pattern has been further feeding by the spread of the digital culture, which provides the common operational framework for converging a number of different disciplines. It focuses indeed on the heuristic method, and it is featured by a tactical approach based on trial-and-error mode and on self-education (Carpo, 2017; Di Biase, 2016; Rabinovitz \& Geil, 2004).

These remarks highlight the need for a new cognitive ground for science, especially focusing on the evolving relationship between the digital culture and the anthropogenic environment (Losasso, 2020). In order to do this, studies in the fields of the natural sciences, humanities and landscape design posited the concept of "Ecological Thinking" as the conceptual ground for the Anthropocene: "the most important epistemological framework of our age" (Hight, 2014), and more in general a key concept for operating within the complex systems (Reed \& Lister, 2014). Ecological Thinking is a kind of thinking that "seeks to eliminate the traditional dichotomy separating

\footnotetext{
${ }^{1}$ Ervin Lazlo, especially, foresaw the innovative figure of the "scientific generalist". The latter is committed to compose the advances produced by the "specialist scientists" within new creative frameworks. This is also the premises for implementing the so-called, meta-science (Lazlo, 1985).
}

M. Rigillo ( $\varangle)$

University of Naples, Napoli, Italy

e-mail: marina.rigillo@unina.it

L. Amenta et al. (eds.), Regenerative Territories, GeoJournal Library 128, https://doi.org/10.1007/978-3-030-78536-9_18 
humanity (as subject) and nature (as object), as a route to understanding diverse, complex, multiply interconnected milieu" (Code, 2006, p. 27). Ecological Thinking is something more than a new theoretical concept. It represents the cognitive tool to govern the relationships within and among systems; it aims at appreciating differences and similarities, and it allows us to understand circularity more than causality (Bateson, 1979).

Looking that way, it is possible to state that ecological thinking is the paradigm shift of the contemporary scientific research, and specifically for the design theory (Code, 2006; Grierson, 2009). In fact, the design discipline is by definition a multidisciplinary domain, in which art and technology establish an open grammar of unexpected combinations by which realizing the "Darwinian evolutionary view of innovation" (Naam, 2013, p. 8). More in general, design brings together ideas not belonging to a single field of research, and it digs out innovative solutions (somehow embedded) thanks to both heuristic and collaborative processes (Carpo, 2017; Manzini, 2015). As steadily founded in the domain of techniques and creativity, design emerges as an effective tactic for shaping sustainable scenarios. It is far engaged in both social and ecological innovation, and it claims for a pioneering role as the creative agent of the contemporary challenges, so modifying the relationships between the "existing assets (from social capital to historical heritage, from traditional craftsmanship to accessible advanced technology) with the aim of achieving socially recognized goals in a new way" (Manzini, 2015, p. 11).

Within the field of the design disciplines, landscape architecture first guessed the importance of such cultural shifts. The 1999 competition for the Downsview Park in Toronto, Canada, represents the turning point in applying the system theory to design process. Here the assumption of systemic approach led the five finalists to implement the concepts of unpredictability and uncertainty as a key part of the project outcomes. The inherent complexity of the site led the design teams out to abdicate to provide fully defined project layouts, preferring instead to let developing the relations between nature and technology on its own. This tactic also implemented the ecological activation of new, and site-specific dynamics between the place and its inhabitants, including animals and vegetation.

The Downsview Park competition is a sort of "manifesto" for the landscape architecture design, as it defines the key points of current theoretical debate: the fascination for the emergent ecologies (as progressive, independent evolution of the design setting); the acceptance of "unpredictability", as part of the environmental potential (as it continuously shapes the site along times); the new opportunities in the relation between Nature and Technology, notably those inferring the digital domain (Cantrell \& Holzman, 2016; Czerniak, 2001). The capacity of managing huge amounts of open data, as well as the opportunity of implementing on-field information (thanks to a range of digital devises able at sensing, visualizing and processing information) gave new emphasis to the scientific approach of design project making the latter as "a point of tangency between the production of scientific models (through testing and falsification) and the symmetrical activity of design (through model making and matching)" (Waldheim, 2006, p. 8). Their creative design enhances responsiveness as a key requirement for the built environment, as well as the digital sensors 
embedded into construction materials allow to measure and control the effective benefits of the technological innovation on the anthropogenic habitats (Brownell, 2010). Therefore, such new opportunities enhance the terms "responsiveness" and "collaborative", either referred to the capacity of updating the design patterns, using digital devises as facilitators of the interactions between Humans and the other living and the non-living forms (Antonelli, 2019; Coccia, 2018; Corner, 1997).

According to these remarks, the paradigm shift is not only due for the amount of the information available, but rather for the provision of different operational patterns: the contemporary habitats have been rapidly evolved into techno-social environments, whose configurations do not only depend by the availability of data set, rather by the ability to develop "tailor-made" patterns that meets global and local needs.

Further, the combination of ecological thinking and digital technologies establishes the new epistemological grounds for design, and defines the operational framework by which overcomes the typical separation between artificial and natural. Notably, the capacity of producing creative hybridization between biotic and abiotic component seems to be the new frontier in the field of technological design and material engineering. The term hypernatural, proposed by Blaine Brownell and Marc Swackhamer in 2015, introduces the idea of a co-evolutionary process between nature and science, looking at humans' technological capacity as a real opportunity for making biotic ad abiotic systems working together: "The ultimate aim of technology is not antinatural: it is hypernatural. It involves working directly with natural forces and processes - rather than against them - in order to amplify, extend, or exceed natural capacities" Brownell \& Swackhamer, 2015, p. 18). Further, the main progresses in transferring hybridization into the construction sector require to fully include new material categories (Transmaterial, as for Blaine Brownell terminology $)^{2}$ emerging from the creative combining of recycled materials, digital tools and biological matter.

Looking that way, the work of the Mediated Matter research group at the MIT, Boston, Massachusetts provides an outstanding example for this new approach. As for the term "Hypernatural", the notion of "Material Ecology" evokes the understanding of technology as a part of the co-evolutionary process between culture, science and nature. The focus goes to both design and material engineering, and it enhances the concept of "material ecology" as key point for defining unprecedented products coming from collaborative expertise (notably biology, computing, and materials engineering). The "Living Material Library ", produced within the MIT Lab, explores the field of digital morphogenesis, and gives an unprecedented emphasis to "the ability of living organisms to sense and respond to their environments" (https:// www.media.mit.edu/projects/living-materials-library/overview/).

More advances in material engineering and design come from the research on organic concrete. The latter has even more understood as an effective opportunity for reducing anthropogenic impacts, notably those related to climate change. The production of multi-layered cement able at interrelating the internal biological

\footnotetext{
${ }^{2}$ See more at http://transmaterial.net/.
} 
microstructure with the abiotic ones improves the surface's performances, and the capacity of the concrete elements to absorb the atmospheric CO2. ${ }^{3}$ Similarly, the Israeli firm ECOncrete has patented, and widely tested, an environmental sensitive concrete especially designed for marine habitats. Such innovative material has been designed as a high quality and cost-effective concrete product. It is featured for being a typical precast or cast-on-site concrete product, engineered for quickly adapt to the marine habitats, both for the properties of the aggregate specific (a mix of biotic and abiotic components), both for the ecologically-based morphology of the different products. $^{4}$

\subsection{Recycling Construction Debris for Producing New Anthropogenic Soils}

Such a new idea of materiality also increases the opportunities for implementing hybrid natures within the urban environments. The need of regenerating neglected areas (such as brownfields and/or former landfills), together with the growing importance of permeable and evapotranspiring soils in the cities (due to the need of providing ecosystem services) gives more interest to processes and techniques aimed at designing anthropogenic soils. In fact, the demand for implementing the stock of evapotranspiring soils in the cities is widely recognized in literature as the starting point for improving climate adaptation and city's resilience (Nelson et al., 2007; MEA, 2005; Niemela, 2011). Further, the urban redevelopment is often associated with relevant operations of environmental upgrade (including soil regeneration), which boasts a comprehensive socio-economic change in the cities land-use, enhancing lifestyles standards and the real estate values especially in the less performative urban areas (Costanza et al., 2014; Potshin \& Haines-Young, 2010; Rigillo et al., 2016; TEEB, 2011).

Urban soils are by definition: "a soil material with a non-agricultural man-made surface layer more than $50 \mathrm{~cm}$ thick, that has been produced by mixing, filling, or by contamination of land in urban and sub-urban areas" (Bockheim, 1974, cited in Craul 1992, p. 86). The scientific acceptance of the urban soil as an engineered product even supports the introduction of the "technosols" typology within the World Reference Base (WRB) for Soil Resources in 2006. These soils are defined by the IUSS Working Group WRB, as "Soils modified by human activities (other than farming) and by human additions (artifacts), in the artificial environments associated with urbanization (roads and parking lots for example) and industrialization" (Chesworth

\footnotetext{
${ }^{3}$ See the Bio-receptive concrete panels developed by the Structural Technology Group at the Universitat Politècnica de Catalunya (UPC). This product is made by two types of cement: standard Portland cement and magnesium phosphate cement, which is slightly more acidic and thus conducive to biological growth. This technology allows the growth of small mosses, fungi, lichens, and microalgae http://transmaterial.net/biological-concrete/.

${ }^{4}$ See more at https://econcretetech.com/about-econcrete/\#.
} 
\& Spaargaren, 2008), and they are listed "by design, [...] as either Ekranic (sealed), Linic (lined), Urbic (rubbly), Spolic (industrial wastes), or Garbic (organic waste)" (Rossiter, 2007). Similarly, the Anthropocene Working Group in 2019 (AWG) highlights an unprecedented hard soils typology described as "technofossils". The term is a scientific neologism aimed at explicating the existence of such new kind of hard materials, which will be recognized by future archaeologists as one of the main tracks of the current civilization. As stated in the AWG Report, "they will persist for millennia or longer, and are altering the trajectory of the Earth System, some with permanent effect. They are being reflected in a distinctive body of geological strata now accumulating, with potential to be preserved into the far future" (AWG, 2019; Zalasiewicz et al., 2014).

An extended definition of urban soils come from the introduction of the term "anthropogenic soil". The latter is aimed at posing the concept within the broader context of the human-altered soils either if not in the strictly urban context (notably peri-urban). Further, more recent definitions of urban soils (Morel et al., 2017) enlarge this typology to a wider range of soils including those relatively undisturbed or not yet altered by human activities or pollutants, if located in the urban areas (Pouyat et al., 2020).

The relevance for the evolving conceptualization of urban soils is due to the increasing awareness of the benefits provided by such "brown infrastructure" in the city environments. Even in the case of human-altered soils, the latter plays a key role in reducing climate impacts as well as in improving safe and healthy spaces. As far anticipated by the studies in the field of urban ecology, what is important now is the capacity of re-thinking the whole urban components (biotic and abiotic) within the common understanding of the cities as part of the Anthropogenic Biomes. Urban soils are then going to become a sort of eco-engineered resource, designed for providing a wide range of services, including the ecological ones, for sustaining the cities environment (Pauleit \& Breuste, 2011). According to these remarks, design operations must be addressed at providing an innovative framework for the human-environment interrelations, also developing new ecologically oriented products which efficiency will be mainly related to the number and typology of the benefits provided.

Within the many, existing design typologies of anthropogenic soils in cities (i.e.: green roofs, de-sealed soils, soil-remediation, etc.), special attention goes to the production of new human-made soils. Here, the design approach properly refers to the hybridization models, due to both the converging of expertise and tools, and of the choice of the material.

In general terms, the technological soil design starts from the soil's layers (properly horizons, or pedon as for the scientific glossary), according to the typical physical, environmental, and chemical characteristics of the site. Horizons are strategically designed to ensure the mixture of mineral components, biological components, and organic matter (Craul, 1999). Each soil layer must be consistent with the soil ecological functions, and its design implies compliance with the soil consistency, the soil structure, and the input of organic components for plant-available nutrient storage. These requirements correspond to a wider set of indicators aimed at complying with both technological and biological efficiency. Basic indicators are 
those related to the efficient growth for vegetation and trees such as the soil consistency, the permeability index, the PH characterization. More indicators concern the horizons texture and the organic matter content, according to the aim of improving buffering and filter functions of the soil, as well as the run-off management. Specific technological indicators, however, regard the slope stability, the soil resistance, and the interaction with the urban infrastructures and with land-uses.

Further specifications refer to the specific soil design product, that it is to "topsoils", or alternatively to "totally designed soils". The latter especially infers the entire soil profile, designing the several soil horizons according to their specific, proper sequence and functional continuity (Craul, 1999). As part of the category of the designed soils, the "sustainable soils" are those "comprised entirely by of recyclable products alone or in a mixture with derelict soil material [...] It contains little, if any, non-renewable resources" (Craul, 1999, p. 107). Sustainable soils therefore referred to the soil material characteristics, with special attention to the productive cycles of resources and flows, and even to local-based supply chains. ${ }^{5}$ Restrictive constraints for this kind of soil come from regulatory requirements, due to compliance to safety and health standards, especially when the chemical and physical composition of the waste materials is unknown, or when it has high variability.

Despite that sustainable soils have been empirically built along history, ${ }^{6}$ the need of controlling the whole life cycle of the designed soil process steers the operational approach towards an integrated real-time information (from design to site operations, and later the monitoring of its in-situ performances). In fact, the design process has been strongly implemented by digital technologies, as for the augmented capacity of sensing and processing data, as for the capacity of modelling and simulating the project results. Such new opportunities in managing on-field data effectively support the scientific approach to soil design.

According to these remarks, both lab tests and on-field tests have become part of the design process. They must be planned with the aim of matching soil specifications with the site constraints, including those depending on the vegetation palette, and other tests related to soil stabilization, run-off control and sediment control. As part of such protocological pattern, the soil design process defines a complex feedback loop between nature, technologies, and objects, creating conditions for enhancing site specificity as well as for engaging new relations between the site and its users.

According to the comprehensive goals of the soil design, further aims concern the reduction of the natural resource exploitation together with a general waste decrease (thanks to the recycle and reuse of C\&D and organic waste). This seems to be a winwin strategy for providing both ecological efficient urban surfaces and reducing waste

\footnotetext{
${ }^{5}$ Some example of materials available for sustainable soils are listed by Craul as: "Sand from river dredging or sand pits or recycled ground glass; Composed Organic material derived from biosolids, selected municipal yard wastes, food processing sludge, and so on; derelict soil material not otherwise useful such as selected mine tailings, basal glacial till, and so on; Dehydrated washing from aggregate plants, certain smoke-stack, fly ashes, and so on" (Craul, 1999, p. 107).

${ }^{6}$ War World II bombing debris management typically used C\&D waste as hard soils, shaping artificial hills (rubble mountains) in the German cities (see https://en.wikipedia.org/wiki/Schutt berg).
} 
production. This strategy is in line with the EU 2011 Roadmap to a Resource Efficient Europe that boosts for producing more value with less input, and for managing material resources more efficiently throughout their life cycle (EU, 2011 quoting in EEA report, 2016, p. 8). In order to do this, the design of anthropogenic soils can be intended as a new circular product for divesting the typical "take-make-dispose" approach (EEA, 2016, 2017), facilitating the "transition to a more circular economy, where the value of products, materials and resources is maintained in the economy for as long as possible, and the generation of waste minimised" (EEA, 2016, p. 25).

\subsection{Collaborative Processes for Designing Anthropogenic Soils}

As introducing the report about the effectiveness of the circular policies within Europe, the 2016 EEA document states "the factors and concerns reported by countries as driving their work on material resource efficiency policies roughly fall into three groups: economic interests, environmental concerns and regulatory requirements" (EEA, 2016, p. 10). Especially for the anthropogenic soils, the constraints and prejudices about environmental risks (mostly referred to the typical NIMBY syndrome) reduce the opportunities of using construction debris for producing technological soils.

In order to overcomes these problems, the Italian team of REPAiR research has worked for connecting the operational soil design with a local-based network aimed at involving the main subjects of the waste supply chains. Either public and private sectors have been engaged as a prime expert group with the aim of deepening benefits and criticalities in replacing C\&D waste as part of new anthropogenic soils. The design strategy aims at outlining an effective operational protocol for creating a stable connection between the landscape project and the whole demolition process. It works on the concept of eco-innovation as in the EU definition: "Eco-innovation refers to all forms of innovation-technological and non-technological-that create business opportunities and benefit for the environment by preventing or reducing their impact, or by optimizing the use of resources" (EC, 2012).

Therefore, circularity refers to multi-scaling design approaches and to innovative models of designing products, processes, and projects. Notably, the research considers sustainable soils as a further product of circular-based supply chains, and it finalizes the design process to both implement the technological requirements and overcome criticalities embedded in social and regulatory contexts.

The focus has specially given to the $C \& D$ waste and to organic waste as effective anthropogenic resources to implement an inclusive and circular waste metabolism due to either the waste typologies are indeed in the priority list of the EU Action Plan for the Circular Economy (COM (2015) 614 final) because of the value of their supply chains. 


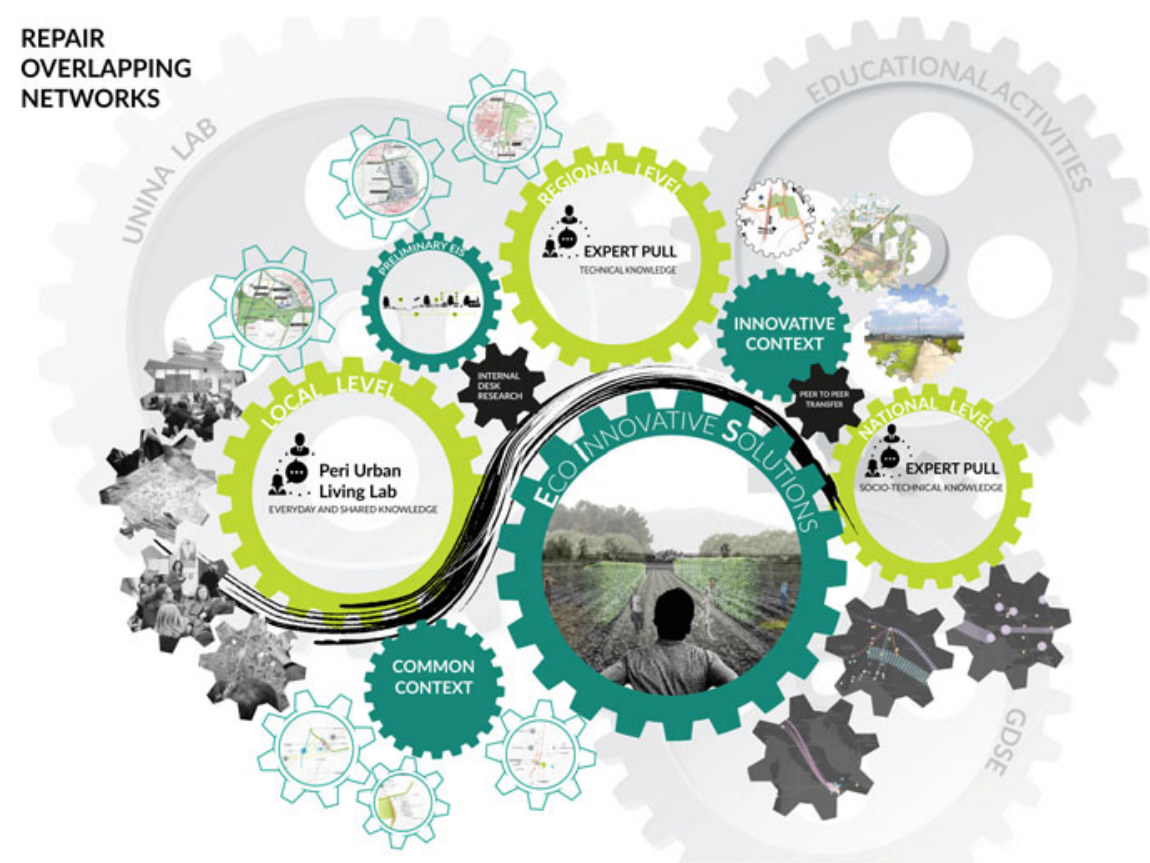

Fig. 18.1 Logical pattern for designing the overlapping networks

The research designs a collaborative process for producing anthropogenic soils thanks to the implementation of a locally based waste supply chain. As part of the wider design approach, the project develops a proper method for involving peers and stakeholders, designing a collaborative network for advancing in the co-design experiences. In operational terms, a number of Peri-Urban Living Labs (PULLs) were realized since the beginning of the project in 2016 (REPAiR, 2018). The latter aims at facilitating the knowledge transfer, according to the Lab participants specific. ${ }^{7}$ The pattern adopted has named "overlapping networks", and it has designed as distinctive framework where both expert and not-expert subjects could merge different competences and wills (Fig. 18.1).

The purpose of these networks is to collaborate for shortening the supply chains of both C\&D waste and organic waste. Such a method enhances co-designing as the operational driver of new "protocological" architecture (Burke, 2007), aimed at validating both products (techno-soils) and process (waste supply chain) within a sort of

\footnotetext{
${ }^{7}$ The PULL participants are technical members of the Regional Authority, professionals in the field of waste management, small local companies working in the urban waste management, academics from selected Italian Universities.
} 
"evidence-based" design approach (Burke, 2007). ${ }^{8}$ The term refers to the objectification of methodological steps, and it is strongly based on the information/decision relationship, as well as to the logical sequence of the design process. Further, the term highlights the importance of standardizing the collaborative decision model within the landscape design, enhancing the relevance of a scientific approach in co-design by which validate (or falsify) the project's results.

In operational terms, the networks have been organized thematically with the aim of stressing the diverse competences of the groups involved. Researchers acted as agents of communication streamlining the design process thanks to the digital tools support (i.e.: GIS, GDSE, scenarios modelling), so that participants can feel fully engaged for providing and validating effective solutions.

The problem setting has been structured in three phases:
(a) Collaborative Mapping.
(b) Depicting potential scenario.
(c) Programming and design.

The first step has been featured as a collaborative exercise for the site description. REPAiR Labs co-created a GIS tool by which implementing both analytical and qualitative information about the case study area, so that a set of thematic maps was carried out for describing the environmental and physical aspects, together with those related the site perceptions. Such an approach aimed at implementing a more comprehensive understanding of the peri-urban area, and it improves the site description with thematic maps, even those produced thanks to no analytical information. Further, more information has been produced within the REPAiR Labs for recognizing abandoned and neglected areas in the Sample Area (Russo et al., 2019). As part of the Lab's works, the REPAiR researchers implemented a dedicated GDSE system with the official dataset on waste flows.

The main goal of this phase is to streamline the main criticalities affecting waste flows management locally, and in operational terms, the expected results concerned a site sensible mapping.

The second phase is aimed at producing effective proposals for shortening the waste supply chains of C\&D waste and organic waste. Starting with the digital waste flows analysis (C\&D Waste and Organic waste) and by the thematic maps produced, the research groups developed three potential waste supply chains redesign scenarios. The latter were all consistent with the local regulatory systems, as well as with the amount of waste production in the study area, and on the territorial organization. The alternatives were mainly based on both the dimension of the organic waste treatment plants and the opportunities in promoting selected demolition in the regional context.

The result of the Labs discussion is a Master Plan for waste reduction.

\footnotetext{
${ }^{8}$ In deepening the concept of "protocological architecture", Anthony Burke wrote: "Protocol is what makes network and Empire functions; they are formal constructs that provide the vitality of network logics, yet they also identify a territory of control points, super-controlled hubs of potential leverage within a design context where information is exchanged and regulated" (Burke, 2007, p. 71).
} 
According to the latter, the third phase is targeted on deepening innovative strategies for waste management (Rigillo et al., 2020). The research defines an EcoInnovative Strategy (EIS) as "an alternative course of action aimed at addressing both the objectives and challenges identified within a PULL and develop a more Circular economies in peri-urban areas" (REPAiR, 2018). Basically, the researches provided three EIS named as follows:

- RECALL I REmediation by Cultivating Areas in Living Landscapes through Phytotechnologies, that works on soil remediation. Digital sensing and phytotechnologies were designed using typical local crops (Kennenk \& Kirkwood, 2015).

- Re-Compost Land. EIS merges the recycling of organic waste (OW) and of C\&D waste (CDW) within designed topsoils. A short supply chain is also designed by the hypothesis of a network of medium-sized treatment plants, linked to precise peri-urban locations between urban and rural contexts.

- Beyond INERTia. The strategy defines a new protocol of actions for construction debris. It starts with the implementation of the market-and-supply condition locally, and establishes a network of debris delivery points in the case study area. A special protocol for $C \& D$ waste characterization and recycling allows to realize new construction products and even totally designed soils (Fig. 18.2).

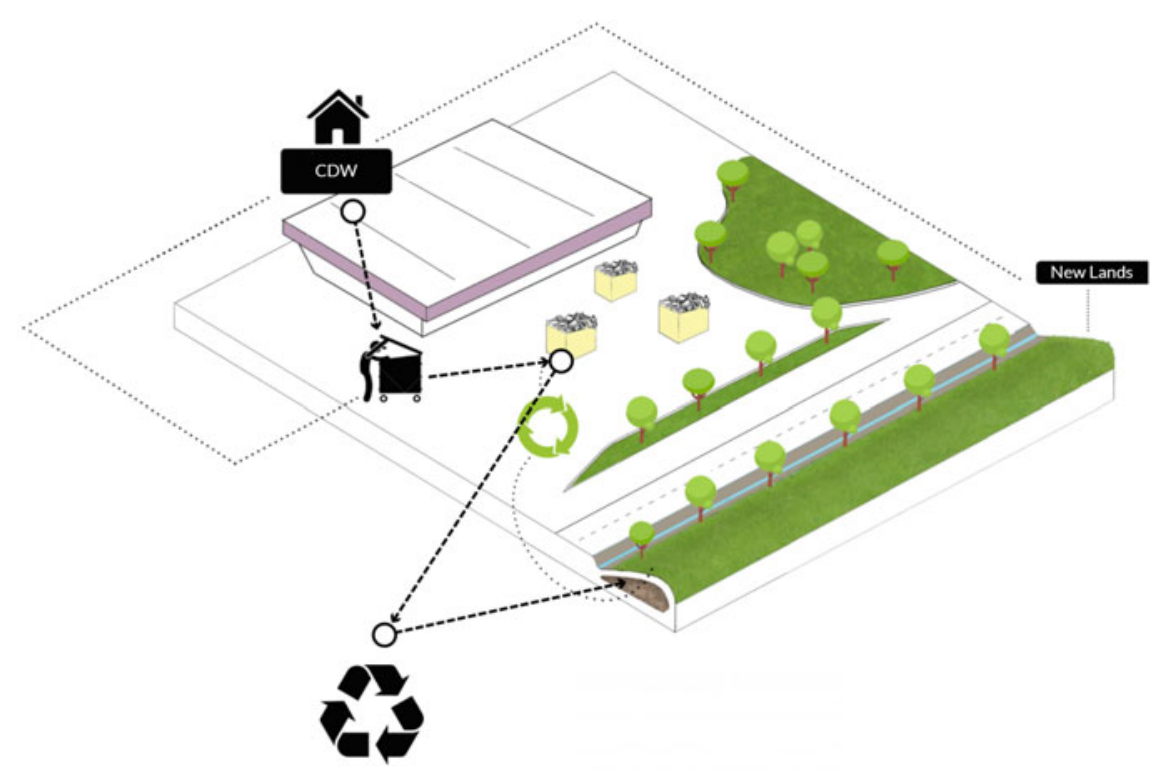

Fig. 18.2 New land production by C\&D Waste recycling 


\subsection{Conclusion}

In the light of these remarks, it is possible to conclude that "the driving element of product and process innovation is often a change in terms of meanings, values, identity: the production process and the social organization play a key role in shaping or re-shaping the architectural product and its language" (Faroldi, 2003, p. 17). The construction process becomes even more complex and systemic. It does not deal with single environmental issue, rather involves integrated changes and decision processes, so that economy, social habit and technological responses are linked together. By this perspective, the technological capacity becomes more dynamic and fluid according to the social requests of eco-innovation, especially focusing on hybridization, which is the cognitive medium for providing research advances both in the fields of design and material engineering.

Looking that way, the insertion of construction debris within the abacus of the anthropogenic resources revises the existing waste supply chains, as well as the design approach. It puts the demolition/ recycling/ reuse cycle into the construction process again, so enhancing a range of different technological solutions, including the unexpensive ones.

Therefore, sustainable soils could be an effective response for achieving the double objective of reducing waste production and claiming for an anthropogenic nature, able at "repairing" damages and impacts in the urban and peri-urban areas (Antonelli, 2019). Notably, sustainable soils can be used as a human-driven support for implementing such artificial nature with the aim of providing ecosystem services, as well as new public spaces for the inhabitants (Rigillo et al., 2020). According to the physical and chemical characteristics of the debris components, as well as the regulatory constraints, sustainable soils can be designed as tailor-made products for the urban environment, in order to facilitate the spreading of specific environmental performances such as planting trees, micro-climate regulation, run-off control, soil buffer capacity: "The hybrid nature of urban ecosystems - resulting from coevolving human and natural systems - is a source of 'innovation' in eco-evolutionary processes" (Alberti, 2015).

The REPAiR project is an opportunity to prove the extent of this paradigm shifts in design and planning. Ecological thinking and collaborative approach have been here adopted as agents of creativity in a complex design framework (Attaianese \& Rigillo, 2021). The results are mostly consistent with the theoretical premises: they carried out innovative design solutions, and orient the collaborative process towards new landscape architecture, widely confirming the relevance of collaborative networks of experts and stakeholders. Further, the research highlights new opportunities for hybridizing biotic and abiotic elements for designing the new technological soils, stressing the C\&D waste and organic waste as potential elements of such artificial nature.

This cognitive upgrade opens up to a new set of human-made resources and construction products including soils. The latter deeply merges the concept of the 
"urban mining" as "a frame of actions for the systematic management of the anthropogenic resources (products and buildings) and waste, featured by a long-term goal for the environmental protection, stressing both the protection of renewable resources and the economic benefits coming from" (Cossu et al., 2012, p. 13) [Author translation].

In operational terms, the study especially deepens the opportunities of testing three typologies of anthropogenic soils, ranging from topsoils to totally designed soils and sustainable soils. The latter are mainly oriented to build a sort of "green-grey infrastructure" along the existing motorways, which became a sort of prime circuit of the C\&D waste recycling (hosting areas for the C\&D waste collection, and for the first treatment of post-construction waste). As part of the REPAiR project results, the anthropogenic soils fully correspond to the EU definition of eco-innovation by the extent of being consistent with the requests of merging together new products and new social-economic processes.

In form of conclusion, the last remarks concern the main perspectives of the research. The results can be immediately oriented towards the analytical (and more effective) implementation of the soil design proposals though out on-field tests. Similarly, a locally based supply chain can be specialized for devising more construction products coming from the $C \& D$ waste recycle, according to the regional regulatory system and to the specific requests of experts and stakeholders. Further, a demonstration project could be carried out within the wider case study area.

A final comment is about the methodological relevance of the REPAiR project. In fact, it defines a more creative role for the design discipline, even more engaged in shaping effective solution for producing sustainable urban environments.

Such an approach fully interprets the challenges of being living the Anthropocene, due to it claims a key role for innovation as the prime conceptual tool for adapting human needs to the Planet care. The research experience enhances: the collaboration between scientists and experts; the co-creation as opportunities for assuming differences and criticalities as a kind of super-understanding of the site and of the project's requirements; and finally the hybridization between biotic and abiotic components as the current frontier of sustainable design. More important, the method adopted for the case study project gives evidence to the common responsibilities in creating effective conditions for a better word, taking advantage of the unprecedented capacity of human technologies in a way that merges people, ecology, ethics and beauty.

According to these points, it is possible to conclude with Paola Antonelli words: "Good contemporary design is also about the ability to connect, identify with and projecting, the awareness that every object and every subject is a node of a complex network of complex systems" (Antonelli, 2019, p. 37, Author Translation). This has been the REPAiR pioneering effort, and we hope it will be successful. 


\section{References}

Alberti, M. (2015). Eco-evolutionary dynamics in an urbanizing planet. Trends in Ecology \& Evolution, 30(2), 114-126. https://doi.org/10.1016/j.tree.2014.11.007.

Antonelli P. (2019). Broken nature. In P. Antonelli \& A. Tannir (Eds.), Broken nature, Catalogo XXII Triennale di Milano, Electa (pp. 16-42).

Attaianese, E., \& Rigillo, M. (2021). Ecological thinking and collaborative design as agents of our evolving future, in TECHNE. Journal of Technology and Environment, 2, 97-101. FU Press. https://doi.org/10.13128/techne-10690.

AWG. (2019) at: http://quaternary.stratigraphy.org/workinggroups/anthropocene/.

Bateson, G. (1979). Mind and nature: A necessary unit. Dutton, New York.

Bocchi, G., \& Ceruti, M. (Eds.). (1985). La sfida della complessità. Feltrinelli Milano.

Bockheim, J. G. (1974). Nature and properties of highly-disturbed urban soils, cited in P. J. Craul (1992). Urban soil in landscape design. Wiley, p. 86.

Brawnell, B. (2010). Transmaterial 3. Princeton Architectural Press.

Brawnell, B., \& Swackhamer, M. (2015). Hyper-natural. Princeton Architectural Press.

Burke, A. (2007). Redefining network paradigms. In A. Burke \& T. Tierney (Eds.), Network practices: New strategies in architecture and design. Princeton Architectural Press, New York.

Cantrell, B., \& Holzman J. (2016). Responsive landscapes. Strategies for responsive technologies in landscape architecture. Routledge

Carpo, M. (2017). The second digital turn: Design beyond intelligence. MIT Press.

Chesworth, W., \& Spaargaren, O. (2008). Technosols. In W. Chesworth (Ed.), Encyclopedia of soil science. Encyclopedia of Earth Sciences Series. Springer. https://doi.org/10.1007/978-1-40203995-9_586.

Coccia, E. (2018), La vita delle piante. Metafisica della mescolanza. Il Mulino.

Code, L. (2006). Ecological thinking: The politics of epistemic location. Oxford University Press.

COM. (2015). 614, L'anello mancante - Piano d'azione dell'Unione europea per l'economia circolare. https://eur-lex.europa.eu/resource.html?uri=cellar:8a8ef5e8-99a0-11e5-b3b7-01aa75 ed71a1.0009.02/DOC_1\&format=PDF.

Corner, J. (1997). Ecology and landscape as agents of creativity, reprint in Reed \& Lister (2018), Op. Cit., pp. 40-65.

Cossu, R., Salieri, V., \& Bisinella, V. (2012). Urban mining: A global cycle approach to resources recovery from solid waste. CISA Publisher.

Costanza, R., de Groot, R., Sutton, P., van der Ploeg, S., Anderson, S. J., Kubiszewski, I., Farber, S., \& Turner, R. K. (2014). Changes in the global value of ecosystem services. Global Environmental Change, Volume 26.

Craul, P. J. (1999). Urban soil. application and practices. Wiley.

Czerniak, J. (eds.) (2001). Case: Downsview Park Toronto. Prestel Harvard Graduate School of Design.

Di Biase, L. (2016). Homo Pluralis. Essere umani nell'era tecnologica, Codice ed., Torino.

EEA. (2016). More from less-Material resource efficiency in Europe. Report No 10/ 2016, Luxembourg.

EEA. (2017). Circular by design. Products in the circular economy. Report No 6/2017, Luxembourg.

EU Commission. (2012). https://ec.europa.eu/environment/eco-innovation/news/index_en.htm.

Faroldi, E. (2003). Nuove prestazioni dell'architettura tra innovazione tecnica e qualità ambientale. In E. Faroldi (Ed.), Progetto, costruzione Ambiente. Dieci lezioni di architettura. Clup Milano

Grierson, D. (2009). The shift from a mechanistic to an ecological paradigm. The International Journal of Environmental, Cultural, Economic and Social Sustainability, 5(5), 197-206.

Haines-Young, R., \& Potschin, M. (2010). The links between biodiversity, ecosystem services and human wellbeing. In C. L. J. Raffaelli \& D. G. Frid (Eds.), Ecosystem ecology: A new synthesis (pp. 110-139). Cambridge University Press.

Hight, C. (2014). Designing ecologies. In Reed \& Lister (Eds.), Op. Cit. 
Kennenk, K., \& Kirkwood, N. (2015). Phyto. Principles and resources for site remediation and landscape design. Routledge.

Latour, B. (2018). Tracciare la rotta. Come orientarsi in politica. Cortina Editore.

Lazlo, E. (1985). L'evoluzione della complessità e l'ordine mondiale contemporaneo. In G. Bocchi \& M. Ceruti (Eds.), Op.Cit.

Lazlo, E. (2008). Quantum shift in the global brain. How the new scientific reality can change us and our world. Inner Traditions.

Losasso, M. (2020). Project production and digital culture. In M. Lauria, \& E. Mussinelli, \& F. Tucci (Eds.), Producing project (pp. 202-207). Maggioli Editore.

Manzini, E. (2015). Design, when everybody designs: An introduction to design for social innovation. MIT Press.

Millennium Ecosystem Assessment. (2005). Ecosystems and human well-being: Synthesis. Island Press.

Morel, J. L., Burghardt, W., \& Kim, K-H. J. (2017). The challenges for soils in the urban environment. In M. J. Levin, K-H. J. Kim, \& J. L. Morel et al. (Eds.), Soils within cities: Global approaches to their sustainable management: composition, properties, and functions of soils of the urban environment (pp. 1-6). Schweizerbart Soil Sciences.

Naam, R. (2013). The infinite resource: The power of ideas in a finite planet. University Press of New England.

Nelson, D. R., Adger, N. W., \& Brown, K. (2007). Adaptation to environmental change: Contributions of a resilience framework. Annual Review of Environment and Resources, 32, 395-419.

Niemela, J. (Ed.). (2011). Urban ecology, patterns processes and application. Oxford Press.

Pauleit, S., \& Breuste, J. H. (2011). Land use and surface-cover as urban ecological indicators. In J. Niemela (Eds.) Op.Cit.

Pouyat, R. V., Day, S. D., Brown, S., Schwarz, K., Shaw, R. E., Szlavecz, K., Trammel, T. L. E., \& Yesilonis, I. D. (2020). Urban soils. In R. Pouyat, D. Page-Dumroese, T. Patel-Weynand, $\&$ L. Geiser (Eds.), Forest and rangeland soils of the United States under changing conditions (pp. 152-158). Springer. https://doi.org/10.1007/978-3-030-45216-2_7.

Rabinovitz, L., \& Geil, A. (2004). Memory bites: History. Duke University Press.

Reed, C., \& Lister, N. M. (2014). Projective ecologies. Actar Publishers and Harvard University Graduate School of Design.

REPAiR Report. (2018). Handbook: how to run a PULL, Deliverable 5.4. EU Commission Participant portal. Brussels, Grant Agreement No 688920.

Rigillo, M., Boccia, L., Capolupo, A., \& Vigo Majello, M. C. (2016). La conoscenza dei suoli urbani per la riduzione del rischio Climate Change. In V. D'Ambrosio \& M. Leone (Eds.), Progettazione ambientale per l'adattamento al Climate Change. Modelli innovativi per la produzione di conoscenza / Environmental Design for Climate Change adaptation. Innovative models for the production of knowledge (pp. 126-135). CLEAN Napoli.

Rigillo, M., Formato, E., \& Russo, M. (2020). SHORT supply chain of waste flows: Designing local networks for landscape regeneration. Detritus, 15, 35-44.

Rossiter, D. G. (2007). Classification of urban and industrial soils in the word reference base for soil resources. Journal of Soil and Sediments. https://doi.org/10.1065/jss2007.02.208.

Russo, M., Amenta, L., Attademo, A., Cerreta, M., Formato, E., Garzilli, F., ... Vittiglio, V. (2019). Short supply chain of waste flows for landscape regeneration in peri-urban areas. In Proceedings Sardinia 2019 / Seventeenth International Waste Management and Landfill Symposium (pp. 111). 30 Sept - 4 October 2019, S. Margherita di Pula, Cagliari, Italy / @ 2019 by CISA Publisher, Italy.

TEEB. (2011). Manual for cities: ecosystem services in urban management, TEEB-The Economics of Ecosystems and Biodiversity.

Waldheim, C. (2006). Strategies of indeterminacy. In recent landscape practice, Public 33 Spring (pp. 80-86). 
Zalasiewicz, J., Barnosky, A., \& Haff, P. (2014). The technofossil. Record of humans. Anthropocene Review, 1(1), 34-43. https://doi.org/10.1177/2053019613514953.

Open Access This chapter is licensed under the terms of the Creative Commons Attribution 4.0 International License (http://creativecommons.org/licenses/by/4.0/), which permits use, sharing, adaptation, distribution and reproduction in any medium or format, as long as you give appropriate credit to the original author(s) and the source, provide a link to the Creative Commons license and indicate if changes were made.

The images or other third party material in this chapter are included in the chapter's Creative Commons license, unless indicated otherwise in a credit line to the material. If material is not included in the chapter's Creative Commons license and your intended use is not permitted by statutory regulation or exceeds the permitted use, you will need to obtain permission directly from the copyright holder. 